\title{
Two Long-Term Follow-Up Cases Preventing Atherosclerosis by Hormone Replacement Therapy-CETP Deficiency and Tangier Disease
}

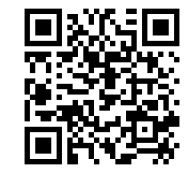

\author{
Kiyomitsu Miyachi¹,4, Minoru Ihara' ${ }^{1}$, Toshitsugu Ishikawa ${ }^{2}$, Belinda Sasse ${ }^{1,3}$, Toshiko Igarashi ${ }^{4}$, Takao Koyama ${ }^{5}$ \\ Keijiro Saku ${ }^{6}$, Katsuhiko Mikoshiba ${ }^{7}$ and Akihiro Inazu ${ }^{8}$ \\ ${ }^{1}$ Keigu Clinic, Japan \\ ${ }^{2}$ Tamachi Tokuei-building Clinic, Japan \\ ${ }^{3}$ Monash Health Rheumatology, Australia \\ ${ }^{4}$ Health Sciences Research Institute, Japan \\ ${ }^{5}$ Koyama Takao Clinic, Japan \\ ${ }^{6}$ Fukuoka University Hospital, Fukuoka \\ ${ }^{7}$ Riken (Laboratory for Developmental Neurobiology Brain Science Institute) Wako, Japan \\ ${ }^{8}$ Kanazawa University, Department of Clinical Laboratory Science, Faculty of Health Sciences Institute of Medical, Japan
}

Received: 制: September 28, 2018; Published: 制: October 10, 2018

*Corresponding author: Kiyomitsu Miyachi, Keigu Clinic, Yokohama, 230-0023, Japan

Abstract

We reported two cases being treated with HRT for the past 7 11 years presenting no progression in atherosclerosis. The first case was diagnosed of having CETP deficiency (homozygosity type) and fibromyalgia at the age of 52 . The HDL-cholesterol level was around $200 \mathrm{mg} / \mathrm{ml}$, CETP DNA point mutation found in intron 14 variant type (A/A) and exon 15 wild type (A/A) were obtained. HRT relieved myalgia and joint pain as well as JFIQ baseline score 91 was reduced to 36, following a 3 months therapy. The second case was diagnosed as a Tangier disease, presenting $1 \sim 2 \mathrm{mg} / \mathrm{dL}$ of HDL cholesterol and a very low level of LDL-C at the age of 52. Her ANA with anti-centromere antibody 80 at the first visit rose to 640 . Depression and shortness of breath disappeared while HRT was continued, However, HRT was discontinued for four years, which made osteoporosis and Altzheimer's disease more progressive. The patient remained in good health as a result of the $\mathrm{E} 32 \mathrm{mg} /$ day and $\alpha$ tocopherol $600 \mathrm{mg} / \mathrm{day}$ that she has been receiving since 2015. In both cases, HRT served as a good therapy for mid aged women in the prevention of atherosclerosis.

Keywords: Tangier disease (TD); Cholesterol ester transfer protein (CETP); High density lipoprotein cholesterol (HDL-C); Estrogen progesterone replacement therapy (EPRT); Estradiol (E2); Estriol (E3); Atherosclerosis

Abbreviation: TD: Tangier Disease; CETP: Cholesterol Ester Transfer Protein; HDL-C: High Density Lipoprotein Cholesterol; EPRT: Estrogen Progesterone Replacement Therapy; E2: Estradiol; E3: Estriol; HRT: Hormone Replacement Therapy; CEE: Conjugated Equine Estrogen; FSH: Follicle Stimulating Hormone; CAVI: Cardio Ankle Vascular Index; ABI: Ankle Brachial Pressure Index; FMD: Flow Mediated Dilatation; PCI; Percutaneous Coronary Intervention; IMT; Intima Media Thickness; CT: Computed Tomography; ERT: Estrogen Replacement Therapy; ANA: Anti-Nuclear Antibody; SRL: Special Reference Laboratory

\section{Introduction}

Atherosclerosis progression is common in mid-aged women [1]. Especially, in the case of ovarium resection and/or hysterectomy, menopausal symptoms including palpitation, sweating, insomnia, depression, dizziness, shortness of breath and so on are more prevalent and occur earlier in women who did operation than in those who performed no operation [2]. Tangier disease (TD) [3] is very rare. However, it is very important to know whether TD will become progressive or not in patients with atherosclerosis. HDL-C is extremely low such that atherosclerosis might develop, but low amount of LDL-C will not induce it. In contrast, CETP depletion [4] occurs with very high level of HDL-C, which is thought to be low activity of ABCA1-mediated cholesterol efflux. Therefore, high amount of HDL-C in case of CETP deficiency is not always protective of atherosclerosis. We have experienced two entirely different types of such diseases and treated with hormone replacement therapy (HRT) for the past ten years and reported the clinical significance of HRT for atherosclerosis. As control, 108 specimens from peri-/ post-menopausal women were included to explore the influence of HRT for total cholesterol, LDL-C and HDL-C. 


\section{Methods}

\section{Influence of HRT for Levels of T Cholesterol, LDL-C and HDL-C}

In addition to the two cases in particular, lipid analysis were performed at 0, 2, 6 and 12 months respectively, with a total of 108 specimen from 95 menopausal women under receiving, tocopherol $\mathrm{N} 600 \mathrm{mg} /$ day, ERT, estrogen progesterone replacement therapy (EPRT) cyclic, EPRT continuous, $17 \beta \mathrm{E} 2$ patch $(0.72 \mathrm{mg} / 2$ days $)$ and $17 \mathrm{E} 2$ oral $(0.5 \mathrm{mg})$ as an estrogen source and dydrogesterone (5 $\mathrm{mg}$ ) as a progestin source were used. Conjugated equine estrogen (CEE) was used exceptionally.

\section{Consent}

Two patients' consent were obtained by documentation and the control patients' consent were obtained orally. This study was approved by the Society of Health Care for Menopause and Ageing in Tokyo.

\section{Detection of Autoantibodies}

Anti-nuclear antibody (ANA) was measured by indirect immunofluorescence using Hep $\square$ cells as a substrate. Most autoantibodies including anti-U1RNP, anti-Sm, anti-SS-A/Ro, antiSS-B/La, anti-Jo1 and anti-Scl 70/Topo1 were measured by ELISA using commercial kit [5]. Anti- IP3Rs antibodies were detected by immunoblot, which has been previously described [6].

\section{Determination of Post-Menopause}

Postmenopausal conditions were estimated by simplified menopausal index (SMI) [7], menstrual condition, and sex hormone levels, including estradiol (E2) (less than $45 \mathrm{pg} / \mathrm{mL}$ ) and/or follicle stimulating hormone (FSH) (more than $27 \mathrm{mIU} / \mathrm{mL}$ ).

\section{Genetic Analysis}

Gene analysis of TD was done in Fukuoka University School of Medicine and reported in 2009 [8]. CETP deficiency (Reference No:4SSU0001) was determined in Tokyo by Special Reference Laboratory (SRL) in 2009.

\section{LDL- Cholesterol Estimation}

In 2008 2009, the amount of cholesterol in LDL was not directly tested, therefore, it was estimated using Fried Ewald's formula [9]. LDL cholesterol $=$ Total cholesterol-HDL C-Triglyceride $/ 5$

\section{Atherosclerosis Examination}

Atherosclerosis examination included ECG, CAVI (Cardio Ankle Vascular Index), ABI (Ankle Brachial Pressure Index), FMD (Flow Mediated Dilatation) [10], PCI (Percutaneous Coronary Intervention), performing first in early visiting, while the second time was after $8 \sim 10$ years.

\section{Results}

\section{Case 1 Female (1955)}

a) Past history: 29y ovariectomy and hysterectomy,

b) Family history: young sister, high HDL- cholesterol

c) Present illness: She had complained of knee joint pain for over 30-years, but knee $\mathrm{x}$ ray revealed no evidence of abnormality.

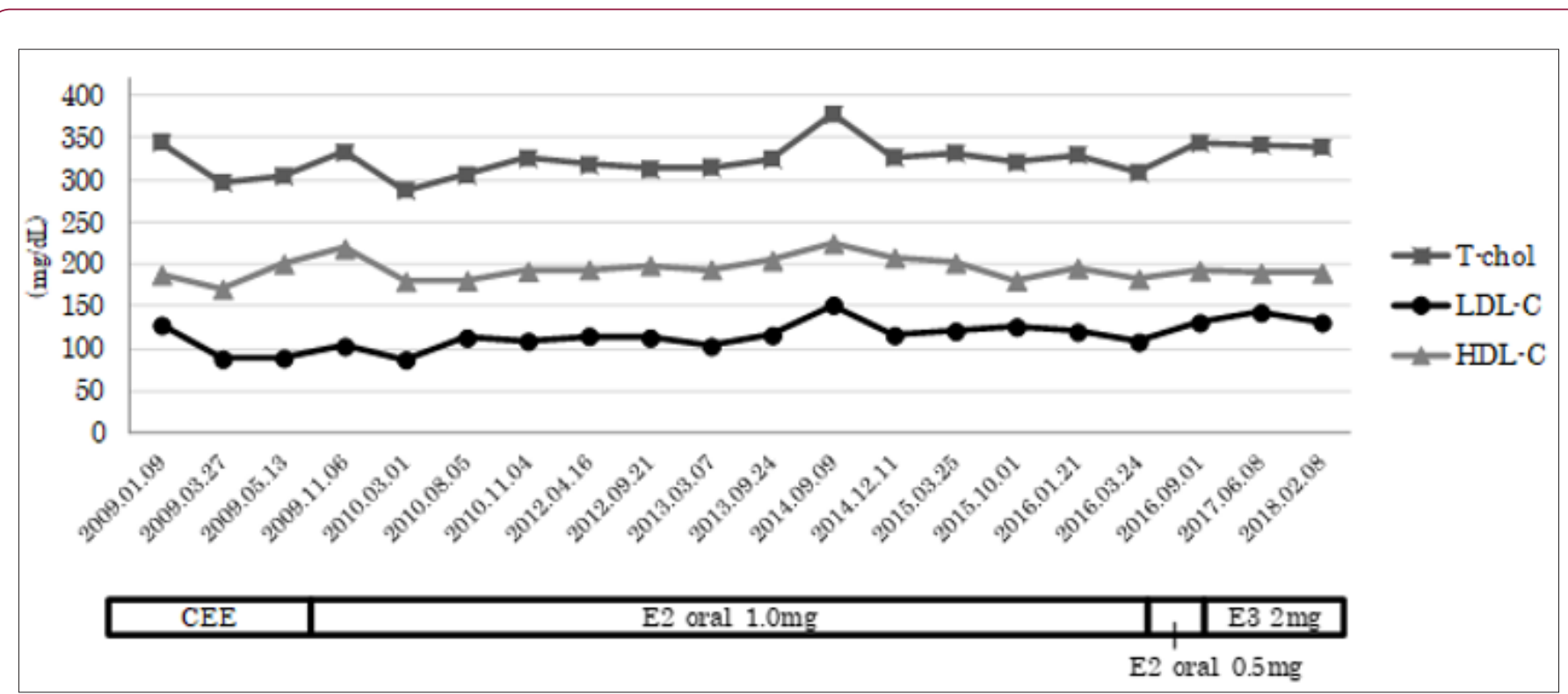

Figure 1: Long term follow-up of cases with CETP deficiency.

She received CEE (conjugated equine estrogen) $0.625 \mathrm{mg} /$ day from January 2009 to October 2009 and changed oral 17 $\beta$ estradiol (Julina)1 $\mathrm{mg}$ / day from November 2009 to june 2016. Julina was reduced to $0.5 \mathrm{mg} /$ day since July 2018. She has never taken statin or other drugs to control lipids. Total cholesterol, LDL-C and HDL.C level used as baseline 100\% in January 2009 were changed to $88 \%, 69 \%$ and $106 \%$ in May 2009. 
In summer 2009, she complained of bilateral knee, wrist and ankle pains and in September 2009, because of bilateral wrist joint swelling, she could not take a walk with a dog. In January 2011, she visited the clinic owing to fatigue, multiple joint pains and myalgia. She was diagnosed as having fibromyalgia and menopausal arthralgia because of depletion in E2 level (16.0 pg/ $\mathrm{mL}$ ) and FSH level (66.7 mIU/mL). Estrogen replacement therapy reduced Japanese Fibromyalgia Impact Questionnaire (J-FIQ) [11] score from 91 to 36 after two weeks therapy and joint pain reduced by $22 \%$ after receiving HRT for 6 months. Laboratory findings and clinical course were presented. For the past 8 years, HDLcholesterol level was always around $200 \mathrm{mg} / \mathrm{mL}$. LDL-C levels were not so high and maintained the normal range. LDL-C/HDL-C was 0.68 on the first visit. E2 levels after receiving ERT were maintained at $40 \sim 90 \mathrm{pg} / \mathrm{mL}$ and FSH levels were maintained at $35 \sim 70 \mathrm{mIU} /$ $\mathrm{mL}$ and the wide spreading pain was reduced to $50 \%$. However, it did not disappear completely (Figure 1). CAVI and ABI revealed 8.9(rt. side)/ 8.6(lt. side) and 1.12(rt. side)/ 1.17(lt. side) in August 2016, suggesting that they were within normal limit. Further FMD showed $11.1 \%$ that was normal range (limit level above $6 \%$ ). Findings from the study of images revealed that carotid artery echogram had no intima media thickness (IMT) hyperplasia and stenosis. Coronary artery computed tomography (CT) scan had no stenosis (in January 2017). Gene analysis was completed in 2011 as shown. One was Intron 14-point mutation $(G>A)$ which causes abnormal splicing (Int 14A mutation). The other was amino acid change (aspartic acid $>$ Glycine) at the position of 442 caused by base change $(A>G)$ at the position of 1506 (D442G mutation)

\section{Case 2, Female, (1953), sales woman}
a) Chief complaint: lethargy
b) Family history: $\mathrm{np}$
c) Personal history: $\mathrm{np}$

d) Present illness: In 1990, She was initially told that her serum cholesterol level was extremely low during the annual health check. In 1996, She was found to have uterine myoma and ovarian cyst. Hysterectomy and ovarian cysts resections were done. At that time, she noticed dry mouth. In 2004, Hemorroid operation was performed and her platelet count was found to be low. In Jan. 2005, she noticed Raynaud's phenomenon at the both fingers. In July 2005, easy fatigability and general fatigue were experienced. In Oct. 2005, she visited the Keigu Clinic.

\section{Laboratory Findings and Clinical Course Were Presented}

During her first visit in October 2005, T. cholesterol $82 \mathrm{mg} / \mathrm{dL}$, HDL-C $2 \mathrm{mg} / \mathrm{dl}$, triglyceride $144 \mathrm{mg} / \mathrm{dL}$, and estimated LDL-C 52 $\mathrm{mg} / \mathrm{dl}$ were obtained. LDL-C/HDL-C was 25.5. ANA 40 with discrete speckle and platelet $8.9 \times 104 / \mu$ l were shown. As sex hormone such as E2 $9.0 \mathrm{pg} / \mathrm{mL}$ and FSH $42.3 \mathrm{mIU} / \mathrm{mL}$ was presented at postmenopausal stage, estrogen replacement therapy (ERT) began. Menopausal symptoms including depression, general fatigue and shortness of breath gradually improved when she started taking low dose of ERT in June 2008. She was referred to another hospital because of cognitive disorder and she remained there until January 2012. As soon as she started noticing depression and general fatigue, she returned to receive E3 $2 \mathrm{mg}$ /day and tocopherol 600 $\mathrm{N} \mathrm{mg/day} \mathrm{(Figure} \mathrm{2).} \mathrm{Moreover,} \mathrm{she} \mathrm{received} \mathrm{bilateral} \mathrm{total} \mathrm{hip}$ replacement (THR) in February and August 2017 because of walking difficulty owing to osteoporosis. She is now active, but Alzheimer's disease is progressing. CAVI and ABI revealed 8.2(both sides) and 1.07(rt. side)/ 1.09(lt. side) in August 2016, suggesting that they were within normal limit. Further FMD showed 7.9\% that fell within normal range. From the study of images, it was revealed that carotid artery echogram had no IMT hyperplasia and stenosis, but coronary artery CT scan presented significant stenosis in the right coronary artery proximal site (in January 2017). Gene analysis was completed in 2011 and shown in previous study [8].

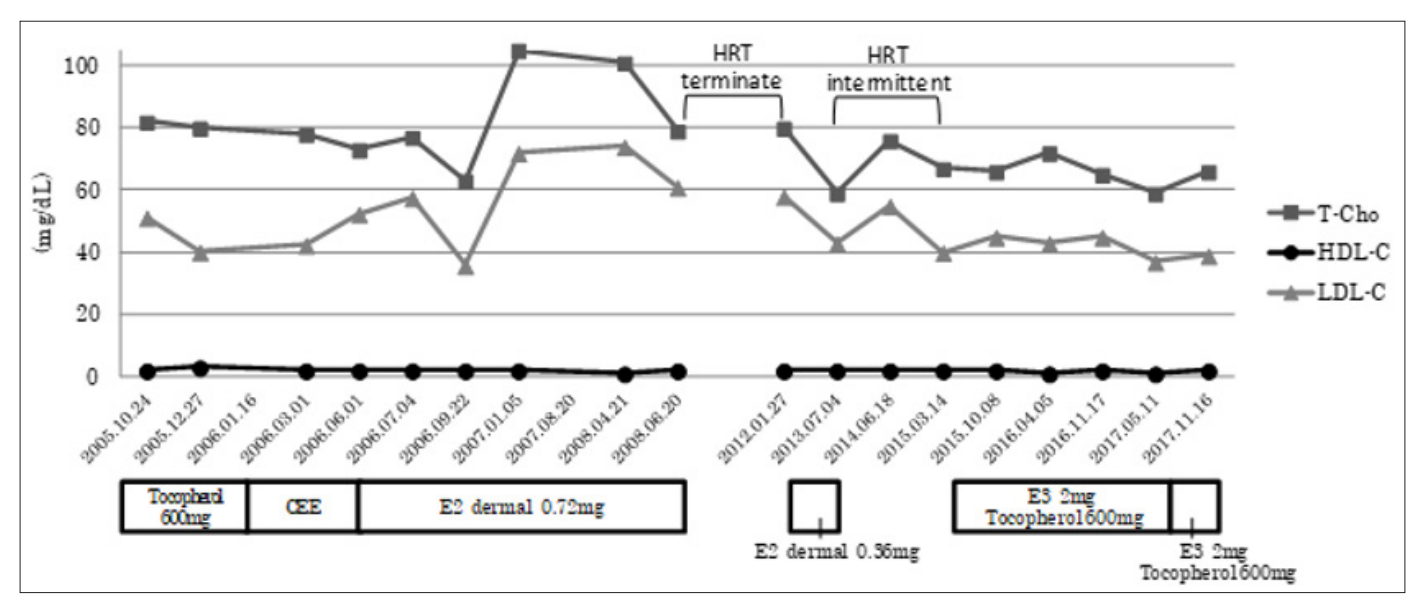

Figure 2: Long term follow-up of cases with Tangier disease.

She received CEE from October 2005 to April 2006 and changed 17ßestradiol patch (estrana) $0.72 \mathrm{mg} / 2$ days from June 2006 to July 2008. Since then, HRT was completely terminated for 4 years. She restarted $0.36 \mathrm{mg} / 2$ days from January 2012 to July 2013, however, she visited intermittently for two years and has received E3 $2 \mathrm{mg}$ / day and a-tocopherol $600 \mathrm{mg}$ since March 2015. Total cholesterol, LDL-C and HDL.C level as baseline 100\% in October 2005 were changed to 97.5\%, 76\% and 150\% in December 2005. 


\section{Discussion}

Menopausal women were popularly known to have abnormal lipid and atherosclerosis. In recent times, HRT at onset of menopause is very useful for the prevention of disease progression such as atherosclerosis and osteoporosis [12]. Regarding association with estrogen and lipid, sufficient estradiol (E2) at child bearing stage maintains normal level of total (T)- cholesterol and LDL-C, in contrast to higher levels in menopausal women. Several reasons were considered. The first reason was that, E2 can regulate the function of 3-hydroxy-3 methylglutaryl coenzyme A reductase, consequently maintaining T-cholesterol level [13]. The second reason is that, E2 decreases the function of hepatic lipase and level of LDL-C, resulting from the interfering conversion of IDL -C to LDL-C [14]. The third reason is that, E2 upgrades LDLreceptor on the surface of the hepatic cell and helps the influx of LDL-C to hepatic cell [15]. The fourth, E2 decreases the function of lipo-protein lipase (LPL) to divide triglyceride into free fatty acid and glycerol, and consequently to low level of LDL-C [16].

The fifth, estrogen enhances the synthesis of Apo-A1 as a major part of HDL-C [17], leading to higher HDL-C. Finally, 17ßE2 activates CETP, consequently, transporting cholesterol ester in HDL-C to LDL-C, in order to prevent atherosclerosis [18]. In this study, we present two different types of lipidosis. One is TD and the other is CETP deficiency. The HDL-C level ranges from 2 to $200 \mathrm{mg} / \mathrm{dL}$ and the LDL-C level ranges from 40 to $140 \mathrm{mg} / \mathrm{dL}$ in CETP deficiency. When we saw these patients for the first time, we wondered whether they could remain for a very long time in good health under these conditions of lipid unbalance. Especially, in the second case of Tangier disease, LH ratio was 25.5, indicating the highly progressive condition of atherosclerosis. Almost ten years have passed since we met them, so we decided to assess their health condition especially atherosclerosis under ERT to oral E3 [19] and $\alpha$-tocopherol N (600 mg/day)/day. Clinically, it was observed that shortness of breath diminished in both patients undertaking ERT. Probably, micro-coronary artery will be well circulated in such conditions [20].

ECG showed a slight abnormality in ST wave depression, but there is no difference between that of 2009 and 2016. In addition, more test such as cardiac echogram, cervical neck echogram, CAVI, and $\mathrm{ABI}$ are not significantly changed. We think ERT is useful for the prevention of atherosclerosis in this case. As for Tangier disease (TD), she had symptomatic Sjogren's syndrome without antiSS-A/Ro, but high titer of ANA with centromere type. In addition, anti-IP3R antibody such as anti-IP3R1 -146.7 (normal <75.6), anti-IP3R2 -60.8(normal< 48.0) and anti-IP3R3-106.6 (normal< 51.0) were all positive [8]. This result propelled us to develop atherosclerosis because of circulating anti-IP3R antibodies reacting with endothelial cells of vessel. However, she has had no history of severe atherosclerosis, under this condition, because HRT might prevent disease progression. Regretfully, HRT was terminated between 2008 and 2012, owing to movement to the nearest doctor. Unfortunately, osteoporosis and depression became so aggravated that HRT was restarted. At present, she is in good health except for walking with cane. Our case including TD presented not only extremely low level of HDL-C, but also low level of LDL-C. The latter LDL-C is so low, suggesting that atherosclerosis is not so progressive. She was over 60 years old, but estriol (E3) $2 \mathrm{mg}$ and atocopherol N $600 \mathrm{mg} /$ day were needed for women's health [21] and aging. Unfortunately, we had no chance to detect anti-IP3R Ab in the first case. Recently, extensive atherosclerosis and bleeding tendency in male Tangier disease was reported, accompanied by Leriche syndrome and uncontrollable bleeding [22].

Finally, we evaluated HRT (ERT 10, EPRT 41) or Tocopherol $\mathrm{N}(600 \mathrm{mg}$ ) (57) for normalization of lipid unbalance during the observation period of 2 months only. Although, resulting from small number, $10 \%$ reduction in LDL-C level by treatment of tocopherol N 600 mg/day, ERT and EPRT resulted in 7.0\%, 30.0\% and 19.5\%, respectively. And $5 \%$ escalation of HDL-C by them resulted in $35.1 \%, 30.0 \%$ and $29.3 \%$, respectively (Table1). However, in this study, T chol, LDL-C and HDL-C level did not change before and after treatment with tocopherol N $600 \mathrm{mg}$, ERT and EPRT cyclic or continuous respectively because $17 \beta \mathrm{E} 2$ patch or oral were used in this study instead of CEE [23]. As a limitation, $\alpha$-tocopherol $\mathrm{N}$ $600 \mathrm{mg}$ did influence $50 \%$ of elevation of HDL-C $(2>3 \mathrm{mg})$ in TD during an observation period of 2 months. However, if more sensitive detection of HDL-C (Apo A1) would be available, precise assessment would be confirmed. Finally, it was reported that HDL-C increased by $138 \%$, and LDL-C decreased by $40 \%$, following 100 $\mathrm{mg}$ of anacetrapib [24]. Although, not available in Japan, we would like to know the efficacy of similar drug for hereditary low HDL-C disease.

Table 1: Percent obtaining over 10\% reduction in T-cholesterol, LDL-C levels and 5\% escalation of HDL-C at 2 months versus baseline under treatment of tocopherol N $600 \mathrm{mg} /$ day, ERT and EPRT cyclic/ continuous.

\begin{tabular}{|c|c|c|c|c|}
\hline & $\begin{array}{c}\text { Case } \\
\text { No }\end{array}$ & $\begin{array}{c}\text { T-Chol } \\
10 \%<\text { down }\end{array}$ & $\begin{array}{c}\text { LDL-C } \\
10 \%<\text { down }\end{array}$ & $\begin{array}{c}\text { HDL-C } \\
5 \%<\text { up }\end{array}$ \\
\hline TF alone & 57 & $7.0 \%$ & $17.5 \%$ & $35.1 \%$ \\
\hline ERT alone & 10 & $30.0 \%$ & $40.0 \%$ & $30.0 \%$ \\
\hline $\begin{array}{l}\text { EPRT cyclic } \\
\text { or } \\
\text { EPRT cont } \\
\text { alon }\end{array}$ & 41 & $19.5 \%$ & $26.8 \%$ & $29.3 \%$ \\
\hline
\end{tabular}

\section{Acknowledgement}

We sincerely appreciate SRL for his assistance in the determination of genetic analysis of CETP deficiency.

\section{Biographical note}

Kiyomitsu Miyachi. MD. Chief doctor for this whole study

Minoru Ihara. MD. Cardiologist performing atherosclerosis tests.

Toshitsugu Ishikawa.MD. An expert for atherosclerosis and lipidosis

Belinda Sasse. MD. Rheumatologist following these patients for 6 months in Japan in 2015 
Toshikon Igarashi.PhD. Technician conducting statistical work

Takao Koyama.MD. Advisor for this work regarding HRT

Keijiro Saku.MD. An expert for atherosclerosis and Tangier disease.

Katsuhiko Mikoshiba.MD. Assisted in the detection of antiIP3R antibody

Akihiro Inazu.MD. Advisor for the study of CETP deficiency

\section{References}

1. Fromm A, Haaland ØA, Naess $H$, Thomassen L, Waje-Andreassen U, et al. (2014) Risk factors and their impact on carotid intima-media thickness in young and middle-aged ischemic stroke patients and controls: the Norwegian Stroke in the Young Study. BMC Res Notes 7:176.

2. Sarrel PM, Sullivan SD, Nelson LM (2016) Hormone replacement therapy in young women with surgical primary ovarian insufficiency. Fertil Steril (7): 1580-1587.

3. Hoffman HN, Fredrickson DS (1965) Tangier disease (familial highdensity lipoprotein deficiency). Clinical and genetic features in two adults. Am J Med 39(4): 582-593.

4. Shinkai H (2012) Cholesteryl ester transfer-protein modulator and inhibitors and their potential for the treatment of cardiovascular diseases. Vasc Health Risk Manag 8: 323-31.

5. Fritzler MJ, Wiik A, Tan EM, Smolen JS, McDougal JS, Chan EK, al. (2023) A critical evaluation of enzyme immunoassay kits for detection of antinuclear antibodies of defined specificities. III comparative performance characteristics of acadmic and manufacture's laboratories. J Rheumatol 30: 2374-2381

6. Miyachi K, Iwai M, Asada K, Saito I, Hankins R, Mikoshiba K (2007) Inositol 1,4,5- tris- phosphate receptors are autoantibody target antigens in patients with Sjőgren's syndrome and other systemic rheumatic disease. Modern Rheumatol 17: 137-43.

7. Melby MK (2006) Climacteric symptoms among Japanese women and men: comparison of four symptoms checklists. Climacteric, 9: 298-304.

8. Miyachi K, Hankins RW, Uehara Y, Zhang B, Saku K, et al. (2009) A postmenopausal patient with Tangier disease developing Sjögren's syndrome. J Rheumatol 36(1): 208-210.

9. Fawwad A, Sabir R, Riaz M, Moin H, Basit A (2016) Measured versus calculated LDL-cholesterol in subjects with type 2 diabetes. Pak J Med Sci 32(4): 955-960.

10. Sherwood A, Bower JK, Mc Fetridge Durdle J, Blumenthal JA, Newby LK, et al. (2007) Age moderates the short-term effects of transdermal 17beta-estradiol on endothelium-dependent vascular function in postmenopausal women Arterioscler Thromb Vasc Biol 27(8): 17821787.

ISSN: 2574-1241

DOI: 10.26717/BJSTR.2018.09.001868

Kiyomitsu Miyachi. Biomed J Sci \& Tech Res

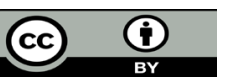

This work is licensed under Creative Commons Attribution 4.0 License

Submission Link: https://biomedres.us/submit-manuscript.php
11. Ablin JN, Wolfe F (2017) A Comparative Evaluation of the 2011 and 2016 Criteria for Fibromyalgia. J Rheumatol 44(8): 1271-1276.

12. Lobo RA, Pickar JH, Stevenson JC, Mack WJ, (2016) Hodis HN Back to the future: Hormone replacement therapy as part of a prevention strategy for women at the onset of menopause. Atherosclerosis 254: 282-290.

13. Trapani L, Violo F, Pallottini V (2010) Hypercholesterolemia and methylglutaryl coenzyme A reductase regulation in aged female rats. Exp Gerontol 45(2): 119-28.

14. Jones DR, Schmidt RJ, Pickard RT, Foxworthy PS, (2002) Eacho PI Estrogen receptor-mediated repression of human hepatic lipase gene transcription. J Lipid Res 43(3): 383-391.

15. Brüning JC, Lingohr P, Gillette J, Hanstein B, Avci H, et al. (2003) Estrogen receptor-alpha and Sp1 interact in the induction of the low-density lipoprotein-receptor. J Steroid Biochem Mol Biol 86(2): 113-121

16. Homma H, Kurachi H, Nishio Y, Takeda T, Yamamoto T, et al. (2000) Estrogen suppresses transcription of lipoprotein lipase gene. Existence of a unique estrogen response element on the lipoprotein lipase promoter. J Biol Chem 275(15): 11404-11411.

17. Lamon Fava S, Micherone D (2004) Regulation of apoA-I gene expression: mechanism of action of estrogen and genistein. J Lipid Res 45(1): 106-112.

18. Bernhard Foger, Rudolf Kirchmair, Christoph Ebenbichler, Josef R Patsch, Sturm W, et al. (2002) Enhancement of Cholesteryl Ester Transfer in Plasma by Hormone-Replacement Therapy Metabolism 51(5): 599-604.

19. Kika G, Izumi S, Mori A, Murano T, Suzuki T, et al. (2009) Beneficial aspect of oral estriol as hormone replacement therapy: consideration on bone and lipid metabolism. Tokaii J Exp Clin Med 34(3): 92-98

20. Sueda S, Kohno H, Yoshino H (2016) The real world in the clinic before and after the establishment of guidelines for coronary artery spasm: a questionnaire for members of the Japanese Cine-angio Association Heart Vessels. Epub ahead of print.

21. Miyachi K, Sasse B, Ihara A (2018) Use of Hormone Replacement Therapy for symptom relief in women with undifferentiated arthritis and menopausal symptoms. eular 2018 THU 0695 as a poster.

22. Muratsu J, Koseki M, Masuda D, Yasuga Y, Tomoyama S, et al. (2018) Accelerated Atherogenicity in Tangier Disease. J Atheroscler Thromb 25(10): 1076-1085

23. Wakatsuki A, Okatani Y, Ikenoue N, Fukaya T (2002) Different effects of oral conjugated equine estrogen and transdermal estrogen $n$ replacement therapy on size and oxidative susceptibility of low-density lipoprotein particles in postmenopausal women. Circulation 106(14): 1771-6

24. Mabuchi H, Nohara A, Inazu (2014) A Cholesteryl ester transfer protein (CETP) deficiency and CETP inhibitors. Mol Cells 37(11): 777-784.

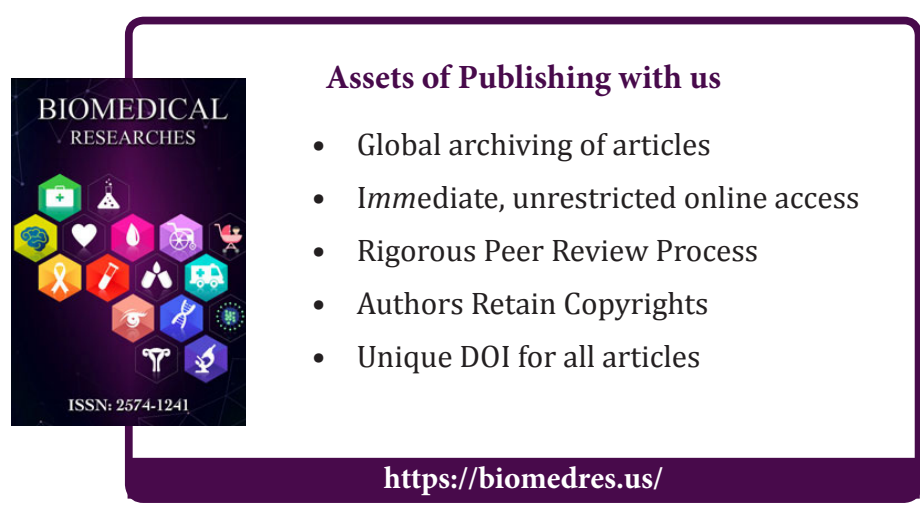

Cite this article: Kiyomitsu M, Minoru I, Toshitsugu I, Belinda S, Toshiko I, Takao K et al. Two Long-Term Follow-Up Cases Preventing Atherosclerosis by Hormone Replacement Therapy-CETP Deficiency and Tangier Disease. Biomed J Sci\&Tech Res 9(5)-2018. BJSTR. MS.ID.001868. DOI: 10.26717/ BJSTR.2018.09.001868. 